Int. J. Electrochem. Sci., 15 (2020) $9146-9153$

International Journal of

ELECTROCHEMICAL

SCIENCE

WWW.electrochemsci.org

\title{
Vertically Aligned Manganese-doped ZnO Nanorods Synthesized on Glassy Carbon Electrode for Detection of Colorants in Soft Drinks
}

\author{
Yongjun Wu ${ }^{1,2, *}$, Nina Xie ${ }^{3}$, Wei Huang ${ }^{1}$, Jingying Chen ${ }^{1}$, Lu Yu ${ }^{1}$ \\ ${ }^{1}$ Maanshan Teacher's College, Maanshan 243041, PR China \\ ${ }^{2}$ College of Chemistry and Materials Science, Anhui Key Laboratory of Functional Molecular Solids, \\ Anhui Normal University, Wuhu 241000, PR China \\ ${ }^{3}$ Maanshan Ninth Junior High School, Maanshan 243000, PR China \\ *E-mail: wyj@massz.edu.cn, wyj0555@yeah.net
}

doi: $10.20964 / 2020.09 .16$

Received: 2 April 2020 / Accepted: 23 May 2020 / Published: 10 August 2020

Synthetic dyes in foods are chemical added to soft drinks and foods during processing or manufacturing. It is very important to monitor artificial colorants in foods due to their potential harm to humans. Herein, sensitive and novel electrochemical sensor based on manganese-doped $\mathrm{ZnO}$ (MZO) nanorods was prepared by one step electrochemical method on glassy carbon electrode (GCE) to determine a synthetic food colorant. Differential pulse voltammetry and cyclic voltammetry were applied to study the electrochemical performance of sunset yellow. As-prepared MZO/GCE was directly used as electrochemical sensor for amperometric determination of sunset yellow, which indicated a high sensitivity of $7.75 \mu \mathrm{A} / \mu \mathrm{M}$ and a low detection limit of $5.2 \mathrm{nM}$. This proposed technique exhibited good stability, outstanding selectivity, and satisfactory reproducibility and repeatability, and also had been applied to simultaneously detect sunset yellow in soft drinks with suitable results.

Keywords: Artificial colorants; Soft drinks; Differential pulse voltammetry; Manganese-doped $\mathrm{ZnO}$ nanorods; Sunset yellow; Electrochemical sensor

\section{FULL TEXT}

(C) 2020 The Authors. Published by ESG (www.electrochemsci.org). This article is an open access article distributed under the terms and conditions of the Creative Commons Attribution license (http://creativecommons.org/licenses/by/4.0/). 